\title{
Recognizing Themselves and Their Friends: Female Children Do It Better
}

\author{
Andrea Peru \\ Department of Neurosciences, Psychology, Drug Research and Child Health, University of Firenze, Firenze, Italy \\ Email: andrea.peru@unifi.it
}

How to cite this paper: Peru, A. (2020). Recognizing Themselves and Their Friends: Female Children Do It Better. Psychology, 11, 936-954.

https://doi.org/10.4236/psych.2020.116060

Received: April 13, 2020

Accepted: June 16, 2020

Published: June 19, 2020

Copyright $\odot 2020$ by author(s) and Scientific Research Publishing Inc. This work is licensed under the Creative Commons Attribution International License (CC BY 4.0).

http://creativecommons.org/licenses/by/4.0/

\section{(c) (i) Open Access}

\begin{abstract}
Three experiments were carried out to investigate how adults and children of different age recognize whole faces, facial features and body parts of themselves and their friends. Results were straightforward in demonstrating that, at least when presented with familiar stimuli, adults did not show any evidence of "self-effect" nor of gender difference. In turn, findings from children groups were consistent with the hypothesis that the abilities to process the different internal facial features follow different, specific, developmental courses and processing of the eyes begins and matures earlier than processing of the mouth and the nose. Furthermore, young perceivers showed a clear self-effect because of which they tended to look at their own face longer than other, familiar identities. Finally, data presented here clearly suggest a developmental advantage for female children in face processing.
\end{abstract}

\section{Keywords}

Face Processing, Facial Features, Gender Effect, Self Effect

\section{Introduction}

Unlike other living species whose behavior is mainly driven by olfactory or auditory cues, humans appear to rely preferentially on visual signals for their perception of the outside world.

Among the others, faces are likely to be the most influential visual stimuli an individual can be exposed to. Indeed, humans are social animals by nature and faces convey most of the relevant information necessary for social interactions and interpersonal relationships (Minnebusch \& Daum, 2009). On one side, "face traits" pass on static information about ethnicity, gender, age, identity, thus allowing individual's recognition. On the other, "face states" transmit dynamic information about face owners' emotional status and intentions. Finally, follow- 
ing an inescapable, even though illogical, propensity to judge a book from its cover, people tend to predict character and psychological traits from facial features (Willis \& Todorov, 2006). Considering that all this amount of information can be captured at a glance, one must get to the conclusion that humans-with the sole exception of prosopoagnosic subjects-are very expert at face processing.

There is now wide consensus that this ability depends on a cognitive module specialized for face perception, located in the fusiform gyrus (Kanwisher, McDermott, \& Chun, 1997). Albeit immature, the cognitive module subserving face processing is already functioning at birth and newborn infants aged few days prefer to look at faces (Morton \& Johnson, 1991) and face-like stimuli (Goren, Sarty, \& Wu, 1975; Valenza, Simion, Cassia, \& Umiltà, 1996) more than at any other visual object. Provided appropriate environmental inputs, the innate predisposition for facial stimuli gradually evolves during infancy and childhood to be completed by puberty (see Macchi Cassia, 2011, for a review). Classically, it has been taught that young (i.e. under age 10 - 12) children perceive faces in a different way than older (i.e. over age 10 - 12) children and adults. That is, while mature perceivers encode faces in a way that integrates features together (holistic effect), developing perceivers use a piecemeal or analytic strategy reliant on distinctive facial features (Schwarzer, 2000). Consistently, the "face inversion effect" according to which upside down faces are much harder to recognize, has been usually found in adult, but not very young perceivers (Carey \& Diamond, 1977). This assumption, however, has been challenged by the demonstration of the face inversion effect among children as well adults. For instance, a recent study mainly aimed to assess the "other-age" effect, demonstrated a face inversion effect, and thus a holistic perception, already in 3-y-o children (Proietti, Pisacane, \& Macchi Cassia, 2013). The empirical evidence, however, is still inconclusive. While some studies support the notion that adult-like holistic perception slowly matures throughout late childhood and adolescence (Carey, Diamond, \& Woods, 1980), but is not fully developed even among 14-year-olds (Mondloch, Dobson, Parsons, \& Maurer, 2004; Mondloch, Geldart, Maurer, \& Le Grand, 2003), other studies are consistent with the hypothesis that facial processing abilities mature between 4 and 7 years of age and their neural bases do not change from late childhood to adulthood (Crookes \& McKone, 2009; De Heering, Houthuys, \& Rossion, 2007).

However, as Ge et al. (2008) correctly pointed out, "The focus on when configural processing emerges, as well as the ongoing theoretical debate regarding the encoding switch hypothesis has eclipsed the research on how children process featural information". Several studies addressed the issue of featural processing in children. Once again, findings are inconsistent. Most of the studies focused on the shift between outer- to inner-face advantage. Campbell et al. (1999) found that, when requested to recognize celebrities' faces, 5- to 13-y-o participants rely more on external facial features (i.e., "outer-face advantage") while the opposite 
was true (i.e. "inner-face advantage") for 14-y-o and 15-y-o participants who demonstrated an adult-like preference for internal facial features, thus confirming their relevance in learning unknown faces (Longmore, Liu, \& Young, 2015). Analogously, an outer-face advantage in the recognition of unfamiliar adult faces was reported in 5- to 9-y-o children (Want, Pascalis, Coleman, \& Blades, 2003), likely because young perceivers find difficult to disregard information from external features of unfamiliar faces (Sugimura, 2013). However, when requested to recognize familiar adult faces, 5-y-o children turned out to rely more on internal than on external face parts (Wilson, Blades, \& Pascalis, 2007). Things do not become clearer when children's instead of adults' faces are used. While Campbell, Walker, \& Baron-Cohen (1995) reported an outer-face advantage for 7-year-olds, but an inner-face advantage for 9-year-olds engaged in the recognition of familiar schoolmates, Bonner \& Burton (2004), found an inner-face advantage in 7-y-o children on a matching task with faces of familiar schoolmates. Inconsistency across studies may be explained by arguing that perceivers rely more on inner or outer features depending on the level of familiarity: the more familiar the face the higher the inner-face advantage (Campbell et al., 1999; Clutterbuck \& Johnston, 2004; Ellis, Shepherd, \& Davies, 1979; Young, Hay, McWeeny, Flude, \& Ellis, 1985). In this vein, the own-age and own-race effects according to which own-age and own-race faces are better recognized than other-age (Kuefner, Macchi Cassia, Picozzi, \& Bricolo, 2008), and other-race (Kelly et al., 2007) faces, respectively, further support the idea that natural experience with faces (Proietti et al., 2013) modulates the development of face recognition abilities during childhood.

Strictly linked with the effect of familiarity, is the so-called "self effect" according to which one's own face grabs more attention than other identities (Brédart, Delchambre, \& Laureys, 2006). Indeed, apart from monozygotic twins who equally recognize their own face and their twin's face (Martini, Bufalari, Stazi, \& Aglioti, 2015), ordinary people show a self-face advantage so strong to persist even when very familiar faces are used or faces are inverted (Keyes \& Brady, 2010). Evidence from brain damaged children demonstrated that self recognition is present from 4 years of age, although the difference self/other is more evident for body than face parts (Frassinetti et al., 2012).

That leads to the issue of how children process the different internal facial features. As usual, empirical evidence is far from being uncontroversial. While there is a wide consensus as to the fact that eyes are the most relevant facial feature for adult perceivers, thus playing a critical role in "what makes faces so special” (Itier, Alain, Sedore, \& McIntosh, 2007), developmental data are still uncertain. Some studies demonstrated a slow development of the ability to process the shape of internal facial features, so that-for instance-8-y-o children are less sensitive than adults to the spacing of internal features (Mondloch et al., 2004). Furthermore, the abilities to process the different internal facial features seem to follow different, specific developmental courses with processing of the 
mouth developed before processing of the eyes as suggested by the fact that mouth turned out to be relatively more influential than the eyes in 5-y-olds' identity judgments of adult faces (Schwarzer \& Massaro, 2001). On the other side, however, there are studies that support the notion that the neural bases of face processing are present from 4 years of age and do not change throughout development (Kuefner, de Heering, Jacques, Palmero-Soler, \& Rossion, 2009). Accordingly, even youngest children show an electrophysiological pattern of face sensitivity similar to that seen in adults (Taylor, Edmonds, McCarthy, \& Allison, 2001), although an adult-like pattern of the N170 is reached only by mid-teens (Taylor, Batty, \& Itier, 2004). The early presence of an eye detector accounts for the fact that, when requested to process familiar own-age faces, young children are better at recognizing the eyes than the mouth and nose regions (Hay \& Cox, 2000; Pellicano, Rhodes, \& Peters, 2006).

Finally, a last point deserves to be considered. Some studies with adult participants reported a women's higher performance in the recognition of faces, although it is not entirely clear whether this advantage depends on a superiority in recognizing only female faces (Lewin \& Herlitz, 2002) or faces in general (McBain, Norton, \& Chen, 2009). Other studies, however, provided behavioral and electrophysiological evidence of a stable male advantage in self-resembling child faces processing ( $\mathrm{Wu}$, Yang, Sun, Liu, \& Luo, 2013). As to children, it is now clear that infants prefer female rather than male faces (Hillairet de Boisferon, Uttley, Quinn, Lee, \& Pascalis, 2014), but empirical evidence is still lacking as to a gender superiority in face processing during childhood.

The present study aims to re-assess adults' and children's ability to recognize their own and their friends' faces as well as body and face parts. In particular, the experimental tests allowed to investigate: 1 ) whether the ability to recognize whole faces as well as body (i.e. hands) and face parts is differentially developed in adults and children of different ages; 2) whether this ability is differentially developed in females and males of different age groups; 3 ) whether the performance of adults and children differs depending on the type of task, namely, whether recognizing "self" items is easier and faster than recognizing stimuli belonging to other people, either of the same or the different gender.

\section{Method}

The study was approved by the Schools' Ethical Committee and carried out in accordance with the Declaration of Helsinki guidelines. The adult participants gave their informed consent. The children's parents gave informed consent and the youngsters gave assent. All of the participants had normal or corrected-tonormal visual acuity, did not suffer or have suffered from neurological or psychiatric problems, and were unaware of the purpose of the study.

\subsection{Participants}

Sixteen (8 females) young adults, thirty-two (16 females) 5-year-old, and sixteen 
(8 females) 8-year-old pupils, volunteered to participate into research, and were involved into different experiments according to the details listed below.

The adults were eight married or engaged couples, linked by a strong, long lasting, friendship relationship so that all of them were very familiar to each other. In turn, both 5- and 8-year-old pupils were attending the third grade of kindergarten or primary school, respectively. Given that all the pupils had been in the same classroom for more than two years, all of them were very familiar with their classmates. In each subgroup of age, the participants were further divided into subgroups of eight (4 females) so that each participant was inserted in a group with three friends of the same gender and four friends of the opposite gender.

\subsection{Stimuli}

The experimental stimuli were black-and-white photographs taken with a digital SLR camera at a distance of about $40 \mathrm{~cm}$ against a white background. For optimal recognition, the subjects were required to have a frontal orientation with the most neutral expression possible during face photographs, and to keep their hands open, palms down with fingers completely extended during hand photographs. In a further step, a commercial software program (Photoshop, Adobe Systems) was used to trim the face images in a standard oval removing salient cues (e.g. ears, hair) as well as specific features (i.e. eyes, nose, mouth) and keep stimuli size and brightness uniform. Each photograph belonged to one of four categories of stimuli: Whole Faces, Features in Isolation, Faces Without One Feature, Faces With Only One Feature. The Features in Isolation category included 5 subtypes of stimuli: eyes, nose, mouth, left hand, and right hand. In turn, the last two categories included 3 subtypes of stimuli each: faces without the eyes, the mouth, the nose, and faces with only the eyes, only the mouth, only the nose, respectively (see Figure 1). Thus, to sum up, there were 12 types of stimuli to be used in various experiments. For brief, they were labeled as Faces, Eyes, Nose, Mouth, LH, RH, noEyes, noNose, noMouth, onlyEyes, onlyNose, onlyMouth, respectively.

\subsection{Apparatus and Procedure}

A commercial software program (E-Prime, Psychology Software Tools, Inc.), was used to implement the experimental paradigm. All the experimental sessions were conducted in a sound- and light-attenuated room using an IBM compatible notebook. Stimuli were displayed on the 14-inch notebook monitor. Participants were comfortably seated in front of the computer monitor so that the distance between the eyes and the center of the monitor was approximately $60 \mathrm{~cm}$. An acoustic warning signal from an acoustic box incorporated in the notebook prompted the subject to start the trial. A response box with four diamondshaped buttons (i.e. top, down, left, right), connected to the notebook via a parallel port was used to record participants' responses. 


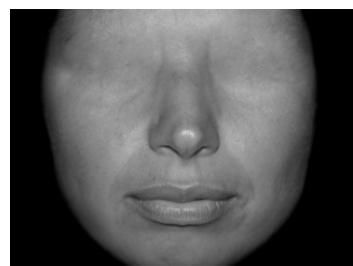

(a) noEyes

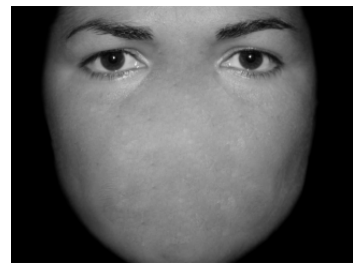

(d) onlyEyes

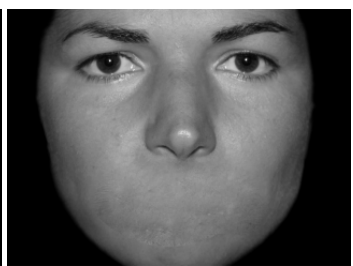

(b) noMouth

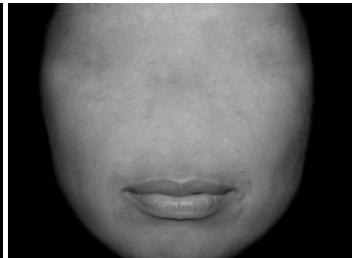

(e) onlyMouth

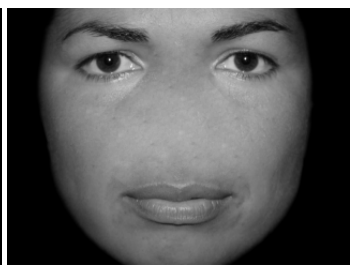

(c) noNose

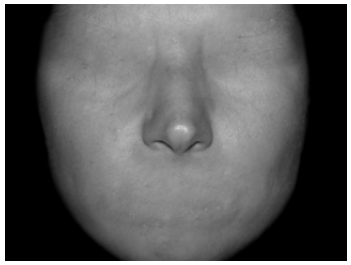

(f) onlyNose

Figure 1. Examples of stimuli used in Experiment 3 face features.

The experimental investigation assessed participants' performance on three tasks: Self, Same Gender (SG), Opposite Gender (OG). In all these tasks each participant was presented only with stimuli derived from his/her own subgroup. In the Self task, the participants had to recognize the pictures of themselves; in the SG and OG tasks they were to recognize the pictures of their best friend of the same or the opposite gender (his/her partner for the adults), respectively. It is relevant to note that the stimuli used in the Self task were the same as those used in the SG task, the only difference being the targets the participants had to identify: stimuli of themselves in the first case, of their same gender best friend in the latter.

Self, SG, and OG tasks were run in this fixed order by all the participants. Before starting each experiment, a few practice trials were administered to ensure that the participant had understood the procedure.

In each trial in each task, stimuli were presented four at a time according to a diamond-shaped arrangement. Thus, in each trial a target and three distractors were displayed. The three distractors were always three stimuli of the same type and gender as the target. The position of the target and distractors were counterbalanced across trials so that in each session the target was presented an equal number of times in the top, right, down and left position. Participants were requested to express their choice by pressing the button corresponding to the position of the supposed target (i.e. left button for indicating the stimulus on the left, right button for the stimulus on the right, and so on). Stimuli were shown until the participant made his/her choice, but not longer than 4 sec.

For each type of stimuli, two dependent variables were recorded: Accuracy, measured in terms of number of errors, and Speed of Response, measured in terms of median reaction time (RT), provided that latencies longer than $4500 \mathrm{~ms}$ and shorter than $250 \mathrm{~ms}$ were considered to be outliers and discarded. In each experiment, however, analysis on RT was run only when the level of accuracy was so high (ceiling effect) to prevent any quantitative analysis. Accuracy and 
RT data were entered in two repeated measures ANOVA and Bonferroni correction for multiple comparisons was applied. Finally, a p-value of $<.05$ was considered to indicate statistical significance.

As said above, each participant was presented only with stimuli from the 8 individuals of his/her own subgroup. Given that separate analyses on the different subgroups of the same age gave always comparable results, these were put together, and statistical analyses were run on the whole sample of participants of the same age group.

\section{Experiment 1 -Whole Faces}

Sixteen ( 8 females) young adults, thirty-two (16 females) 5 -year-old, and sixteen (8 females) 8-year-old pupils were involved in this experiment.

In each of the three experimental sessions (Self, SG, and OG) there were 32 trials, so the target was presented eight times in each of the four spatial positions. Only young adults ran additional sessions in which the same stimuli were presented upside-down rather than upright.

\subsection{Results and Discussion}

Hereafter (Table 1), the detailed results from the three groups of participants (16 participants for each group).

\subsubsection{Adults}

In all testing conditions, participants were extremely accurate. However, although the number of errors they made was too small to be entered into any quantitative analysis, some qualitative observations on their pattern of performance are still possible. First, the number of errors was absolutely negligible with upright stimuli (overall error rate $<1 \%$ ), but markedly increased with upside-down stimuli (overall error rate $=7.3 \%$ ). Second, the number of errors only marginally increased from Self to SG and OG task; namely, the participants' performance did not vary substantially across the different sessions. Third, no significant difference emerged between males' and females' performance.

With regard to the Speed of Response, RT data were entered in a repeated measures ANOVA with Gender (Females vs. Males) as the between-subjects factor, while Task (Self vs. SG vs. OG) and Stimulus Orientation (Upright vs. Upside Down) were the within-subjects factors. The main results were that the factor Gender was far from significance and the three tasks were absolutely indistinguishable from each other. On the opposite, the factor Stimulus Orientation was highly significant $[\mathrm{F}(1,14)=116.1, p<.001]$ because, as expected, across the tasks, responses to upright (mean RT $=1269 \mathrm{~ms}$.) were consistently much faster than responses to upside-down (mean RT $=1792 \mathrm{~ms}$.) stimuli.

\subsubsection{Eight-Years-Old Children}

8-y-o children turned out to be as accurate, although slower, than adults. This at ceiling performance prevented to run any quantitative analysis on accuracy data. 
Table 1. Whole Faces: accuracy (\% of errors) and speed of response (mean RT in ms.).

\begin{tabular}{|c|c|c|c|c|c|c|c|c|c|}
\hline \multicolumn{2}{|c|}{$\begin{array}{c}\text { Task } \\
\text { Stimuli }\end{array}$} & \multicolumn{2}{|c|}{$\begin{array}{l}\text { Adults } \\
\text { Upright }\end{array}$} & \multicolumn{2}{|c|}{$\begin{array}{c}\text { Adults } \\
\text { Upside Down }\end{array}$} & \multicolumn{2}{|c|}{$\begin{array}{c}\text { 8-y-o Children } \\
\text { Upright }\end{array}$} & \multicolumn{2}{|c|}{$\begin{array}{c}\text { 5-y-o Children } \\
\text { Upright }\end{array}$} \\
\hline & & Acc & $\mathrm{RT}$ & Acc & $\mathrm{RT}$ & Acc & RT & Acc & RT \\
\hline \multirow{2}{*}{ Self } & females & 0 & 1339 & 0 & 1750 & 0 & 2173 & 1.2 & 2664 \\
\hline & males & 0 & 1247 & 9.4 & 1730 & 0 & 2313 & 4.3 & 2819 \\
\hline \multirow{2}{*}{ SG } & females & 0 & 1201 & 0 & 1539 & 0 & 1900 & 1.2 & 2293 \\
\hline & males & 1.6 & 1222 & 12.5 & 2167 & .8 & 2201 & 5.5 & 2623 \\
\hline \multirow{2}{*}{ OG } & females & 3.1 & 1278 & 12.5 & 2005 & 0 & 2026 & 2.7 & 2197 \\
\hline & males & 0 & 1326 & 9.4 & 1563 & .8 & 2027 & .8 & 2745 \\
\hline mean & & .8 & 1269 & 7.3 & 1792 & .3 & 2107 & 2.6 & 2557 \\
\hline
\end{tabular}

In turn, analysis based on RT (ANOVA with Gender as the between-subjects factor, and Task as the within-subjects factor) showed that 8-y-o children pupils were faster in responding to both SG and OG than Self stimuli $(p=.026$ and .028 , respectively), so the factor Task reached significance $[\mathrm{F}(2,28)=6.470$, $p=.005]$. The factor Gender was significant as well $[\mathrm{F}(1,14)=5.303, p=.037]$ because females (mean $\mathrm{RT}=2033 \mathrm{~ms}$.) responded faster than males (mean RT $=$ $2180 \mathrm{~ms}$.) in both Self and SG tasks, while no gender difference was observed in the OG task.

\subsubsection{Five-Years-Old Children}

Also 5-y-o children were very accurate, thus making any quantitative analysis meaningless. However, it is worthy to note that while all the females made very few, if any, errors, two males failed to recognize more than $50 \%$ of stimuli across the different tasks.

In addition, several participants found difficult to use the response box, so gave their responses by pointing to the target and the examiner entered the choice on the computer. Because of this, only RT data from sixteen children (8 females) were entered in a repeated measures ANOVA with Gender as the between-subjects factor, and Task as the within-subjects factor. As their older mates, 5-y-o children were faster in responding to both SG and OG than Self stimuli, so that the factor Task showed a clear tendency toward significance [F $(2,28)=3.176, p=.057]$. In turn, the factor Gender was significant $[\mathrm{F}(1,14)=$ 5.303, $p=.037$ ] because females (mean $\mathrm{RT}=2385 \mathrm{~ms}$.) responded faster than males (mean RT $=2729 \mathrm{~ms}$.) in all the tasks, thus making the interaction Gender by Task not significant.

To sum up, only a robust effect of stimulus orientation emerged among adult participants. Not surprisingly, upright stimuli were recognized faster and better than upside-down stimuli (see Valentine, 1988, for a review of the effects of inversion upon face recognition). Furthermore, likely because the task was only 
relatively challenging, with both upright and inverted faces, we failed to observe any evidence of self-face advantage (Keyes \& Brady, 2010) nor did we observe any evidence of the female advantage in face recognition previously reported by other investigators (Cellerino, Borghetti, \& Sartucci, 2004; McBain, Norton, \& Chen, 2009; Sun, Gao, \& Han, 2010).

Things were much more intriguing when children's performance was considered. Both the two groups of children have shown to have a strong task effect, being faster in responding to SG and OG than Self stimuli. At least two hypotheses, not mutually exclusive, can be put forward to explain these apparently paradoxical findings. First, faster responses in SG and OG tasks may simply reflect a practice effect on tasks carried out later (but it should be explained why this effect was only observed between the first and the second, but not between the second and the third task). The second, and more probable, explanation holds that the longer time taken to respond to self-faces may depend on a deeper emotional involvement at work in this session. As demonstrated by Devue, Van der Stigchel, Brédart, \& Theeuwes (2009), when presented with their own face, perceivers tend to look at it longer, rather than to find it faster. Namely, the self-face advantage mainly consists in a difficulty to disengage attention from the self-face rather than in a differential, privileged, processing of it.

Furthermore, unlike adults, younger participants showed a clear gender difference with females of both age groups more accurate and faster than their male peers. Although in need of further substantiation, this result suggests a developmental advantage for female children in face processing. In this vein, it is also relevant to note that while 5 -y-o females performed better than their male peers in all the three tasks, among 8-y-o children the female superiority was observed with both Self and SG, but not OG stimuli. That seems to suggest that, like adults (Lewin \& Herlitz, 2002), older female children are better than male peers in recognizing female, but not male faces.

After experiment 1 , the different age groups were divided into two subgroups: one was to participate into experiment 2 , the other into experiment 3 .

\section{Experiment 2-Face and Body Features}

Eight (4 females) 5-y-o children weren't available so the experiment was carried out on three groups of 8 (4 females) participants each: adults, 8-y-o, and 5-y-o children.

The procedure was absolutely consistent with that adopted in experiment 1 . The only difference was that this time experimental stimuli represented five types of face and body parts (i.e. eyes, nose, mouth, $\mathrm{LH}$ and $\mathrm{RH}$ ) in isolation for a total of 40 trials per session.

\subsection{Results and Discussion}

Table 2 shows the detailed results from the three groups of participants ( 8 participants for each group). 
Table 2. Features in isolation.

\begin{tabular}{|c|c|c|c|c|c|c|}
\hline \multicolumn{7}{|c|}{ 1) Adults ( $R T$ in ms.) } \\
\hline \multicolumn{2}{|c|}{ Task } & Eyes & Nose & Mouth & Left Hand & Right Hand \\
\hline \multicolumn{2}{|c|}{ Self } & 1460 & 2295 & 2226 & 2263 & 2453 \\
\hline \multicolumn{2}{|c|}{ SG } & 1721 & 2446 & 3107 & 2526 & 2773 \\
\hline \multicolumn{2}{|c|}{ OG } & 1912 & 2454 & 2566 & 2455 & 2657 \\
\hline \multicolumn{2}{|c|}{ mean } & 1698 & 2398 & 2633 & 2415 & 2628 \\
\hline \multicolumn{7}{|c|}{ 2) 8-y-o Children (Accuracy \% of errors) } \\
\hline \multirow{2}{*}{ Self } & females & 0 & 18.75 & 6.25 & 31.25 & 25.00 \\
\hline & males & 0 & 81.25 & 12.50 & 62.50 & 56.25 \\
\hline \multirow[b]{2}{*}{ SG } & females & 0 & 12.50 & 0 & 6.25 & 12.50 \\
\hline & males & 0 & 68.75 & 18.75 & 81.25 & 68.75 \\
\hline \multirow{2}{*}{ OG } & females & 0 & 37.50 & 6.25 & 56.25 & 56.25 \\
\hline & males & 0 & 37.50 & 37.50 & 50 & 43.75 \\
\hline \multicolumn{2}{|l|}{ mean } & 0 & 42.7 & 13.5 & 47.9 & 43.8 \\
\hline \multicolumn{7}{|c|}{ 3) 5-y-o Children (Accuracy $\%$ of errors) } \\
\hline \multirow{2}{*}{ Self } & females & 0 & 56.25 & 18.75 & 18.75 & 81.25 \\
\hline & males & 25.00 & 31.25 & 87.50 & 50.00 & 62.50 \\
\hline \multirow{2}{*}{ SG } & females & 12.5 & 75.0 & 37.5 & 75.0 & 68.8 \\
\hline & males & 0 & 56.25 & 87.50 & 100.0 & 93.8 \\
\hline \multirow{2}{*}{ OG } & females & 12.5 & 56.25 & 62.5 & 81.25 & 87.50 \\
\hline & males & 12.5 & 87.50 & 31.25 & 37.5 & 75.0 \\
\hline mean & & 10.4 & 60.4 & 54.2 & 60.4 & 78.1 \\
\hline
\end{tabular}

\subsubsection{Adults}

Adults were extremely accurate in all testing conditions (i.e. overall error rate < $3 \%)$ so their performance was analyzed only in terms of speed of response. The main results were as follows: although females (mean $\mathrm{RT}=2185 \mathrm{~ms}$.) were overall a bit faster than males (mean RT $=2523 \mathrm{~ms}$.), the factor Gender and its interactions were all far from significance. The same was true for the factor task and its interactions. By contrast, the factor Feature was significant $[F(4,24)=4.954$, $p=.005]$, because participants were much faster in recognizing Eyes than any other feature, but it deserves to note that only the difference with LH and $\mathrm{RH},(p$ $=.004$ and .006 , respectively) was significant.

\subsubsection{Eight-Years-Old Children}

Compared to adults' performance, the number of errors markedly increased when the 8-y-o children's performance was considered (overall error rate $=$ 
$29.6 \%$ ). Females turned out to be much more accurate than males (error rate = $17.9 \%$ vs. $41.2 \%$ ) so the factor Gender (but not its interactions) was highly significant $[\mathrm{F}(1,6)=38.244, p<.001]$. The factor Task and its interactions were far from significance. By contrast, the factor Feature was highly significant $[\mathrm{F}(4,24)$ $=11.345, p<.001]$ because 8 -y-o children made no errors in recognizing the stimuli Eyes which then were significantly different from LH $(p=.028), \mathrm{RH}(p$ $=.004)$ and Nose $(p=.005)$, but not Mouth which, in turn, was different from LH $(p=.018)$.

\subsubsection{Five-Years-Old Children}

The number of errors markedly increased when the 5-y-o children's performance was considered. Indeed, they made an enormous number of errors (overall error rate $=52.7 \%$ ) and in many experimental conditions their performance was at chance level or even below. Notwithstanding that females (error rate = $49.6 \%$ ) were a bit more accurate than males (error rate $=55.8 \%$ ), the factor Gender and its interactions were not significant. Moreover, younger children were more accurate in the Self than SG and OG tasks, thus the factor Task was very near to significance $[F(2,12)=3.713, p=.056]$. Needless to say, once again, the factor Feature was highly significant $[\mathrm{F}(4,24)=34.229, p<.001]$ because 5-y-o children were much more accurate in recognizing the Eyes (error rate $=10.4 \%)$ than all the other stimuli $(p<001$ in all cases, but Mouth: $p=.044)$ which, in turn, did not differ from each other.

In summary, findings from experiment 2 are consistent with the notion that face parts are easier to recognize than body parts (Bank, Rhodes, Read, \& Jeffery, 2015) and eyes are the most relevant and recognizable facial feature (Taylor et al., 2001). Indeed, our results are straightforward in demonstrating that processing of the eyes begins and matures earlier, so that, unlike what found by Schwarzer \& Massaro (2001) who used adult faces as stimuli, the eyes turned out to be more influential than the mouth even in 5-y-olds' identity judgments of familiar, children faces (Hay \& Cox, 2000; Pellicano et al., 2006).

The most interesting finding from experiment 2 , however, has to do with the developmental course of the ability to recognize body and face parts presented in isolation. This turned out to be a very difficult task for 5-y-o, but not 8-y-o children, especially if female. That demonstrates that the ability to recognize body and face parts in isolation develops during middle childhood and matures earlier in females than males, likely because females are more involved in human relationships and so more experienced with faces (Ge et al., 2008).

With the aim to investigate to what extent the presence of a face contour could make easier to recognize the different facial features, a third experiment was carried out.

\section{Experiment 3-Faces with or without Features}

Like experiment 2, also this experiment was carried out on three groups of 8 (4 females) participants each: adults, 8-y-o, and 5-y-o children. 
In each of the three experimental sessions (Self, SG, and OG) there were 96 trials, so that for each of the 6 types of stimuli presented (i.e. noEyes, noNose, noMouth, onlyEyes, onlyNose, onlyMouth) the stimulus target was presented four times in each of the four spatial positions. Also in this experiment, adults ran additional sessions with upside-down stimuli.

\subsection{Results and Discussion}

Table 3 shows the detailed results from the three groups of participants.

\subsubsection{Adults}

When presented with upright stimuli, all the participants were extremely accurate across the different tasks. Actually, the number of errors they made was absolutely negligible with all the types of stimuli, but one: onlyNose for which an overall error rate of $25 \%$ was recorded.

Table 3. Faces with and without features. accuracy (\% of errors).

\begin{tabular}{|c|c|c|c|c|c|c|c|}
\hline \multicolumn{8}{|c|}{ 1) Adult subjects } \\
\hline & Task & noEyes & noMouth & noNose & OnlyEyes & OnlyMouth & OnlyNose \\
\hline \multirow{3}{*}{ Self } & Upright & 4.7 & 1.6 & 0 & 1.6 & 0 & 26.6 \\
\hline & & & & & & & \\
\hline & Upside down & 15.6 & 12.5 & 6.3 & 14.1 & 9.4 & 15.6 \\
\hline \multirow{2}{*}{ SG } & Upright & 0 & 1.6 & 0 & 4.7 & 1.6 & 15.6 \\
\hline & Upside down & 18.8 & 14.1 & 7.8 & 15.6 & 18.8 & 34.4 \\
\hline \multirow{2}{*}{ OG } & Upright & 0 & 0 & 1.6 & 1.6 & 3.1 & 32.8 \\
\hline & Upside down & 9.4 & 12.5 & 21.9 & 12.5 & 28.1 & 23.4 \\
\hline \multicolumn{8}{|c|}{ 2) 8-y-o Children Upright stimuli } \\
\hline \multirow{3}{*}{ Self } & females & 21.9 & 6.3 & .0 & 6.3 & 53.1 & 65.2 \\
\hline & & & & & & & \\
\hline & males & 18.8 & 6.3 & 3.1 & 6.3 & 34.4 & 68.8 \\
\hline \multirow{3}{*}{ SG } & females & 15.6 & .0 & .0 & 3.1 & 53.1 & 46.9 \\
\hline & & & & & & & \\
\hline & males & 15.6 & 21.9 & 3.1 & 18.8 & 12.5 & 68.8 \\
\hline \multirow{3}{*}{ OG } & females & 40.7 & 3.1 & .0 & 3.1 & 71.9 & 53.1 \\
\hline & & & & & & & \\
\hline & males & 37.5 & 3.1 & .0 & 12.5 & 34.4 & 34.4 \\
\hline \multicolumn{8}{|c|}{ 3) 5-y-o Children Upright stimuli } \\
\hline \multirow{3}{*}{ Self } & females & 59.4 & 6.3 & 6.3 & 9.4 & 46.9 & 71.9 \\
\hline & & & & & & & \\
\hline & males & 34.4 & 28.1 & 15.6 & 21.9 & 40.6 & 81.3 \\
\hline \multirow{3}{*}{ SG } & females & 43.8 & 9.4 & 9.4 & 6.3 & 56.3 & 81.3 \\
\hline & & & & & & & \\
\hline & males & 40.6 & 9.4 & .0 & 15.6 & 53.1 & 75.0 \\
\hline \multirow{3}{*}{ OG } & females & 71.9 & 3.1 & 3.1 & 12.5 & 62.5 & 71.9 \\
\hline & males & & & & & & 656 \\
\hline & males & 31.3 & .0 & 3.1 & 12.5 & 46.9 & 65.6 \\
\hline
\end{tabular}


As to the speed of response, the main results were as follows: no gender difference was observed across the three tasks. Quite obviously, the factor Presence (2 levels: only vs. no) was significant $[\mathrm{F}(1,6)=23.587, p=.003]$ with "noFeature" (mean RT = 1492 ms.) recognized faster than "onlyFeature" stimuli (mean $\mathrm{RT}=1684 \mathrm{~ms}$.). More interestingly, also the interaction Feature by Presence was significant $[\mathrm{F}(2,12)=4.170, p=.042]$ because the stimuli onlyEyes (mean RT $=$ $1505 \mathrm{~ms}$.) were recognized faster than both onlyMouth (1688 ms.) and onlyNose (1860 ms.) stimuli, while the opposite was true for noFeature stimuli with noEyes (1633 ms.) recognized slower than both noMouth (1441 ms.) and noNose (1402 ms.) stimuli.

Things were quite different when the performance with upside down stimuli was considered. Indeed, too many participants failed to fulfill the inclusion criterion requiring at least $50 \%$ of correct and reliable responses to any experimental stimulus, so their performance was analyzed only in terms of accuracy. Females were a bit more accurate than males and all the participants were overall more accurate in recognizing Self than SG and OG stimuli. Moreover, noFeature stimuli were recognized easier than only Feature ones. Notwithstanding this, no main factor nor any interaction was significant, indicating that all the differences tended to disappear with upside down stimuli.

\subsubsection{Eight-Years-Old Children}

Although 8-y-o children made much more errors than adults, their pattern of performance was very similar to that of older participants with no evidence of Gender or Task effect, but a high significance of the factor Presence $[F(1,6)=$ $210.162, p<.001]$ with noFeature (error rate $=10.9 \%$ ) recognized much better than onlyFeature stimuli (error rate $=35.9 \%$ ) and of the interaction Feature by Presence $[\mathrm{F}(2,12)=44.342, p<.001]$ due to the fact that onlyEyes (error rate = $8.3 \%)$ were recognized much better than both onlyMouth (43.2\%) and onlyNose (56.2\%) stimuli, while the opposite was true for noFeature stimuli with noEyes (25\%) recognized much worse than both noMouth $(6.8 \%)$ and noNose stimuli $(1 \%)$.

\subsubsection{Five-Years-Old Children}

The pattern of 5-y-o children's performance was qualitatively undistinguishable from that of 8-y-o children, the only difference being the slightly larger number of errors made by younger participants. Thus, neither the factors Gender and Task, nor their interactions were significant. In turn, once again, the factor Presence $[\mathrm{F}(1,6)=99.954, p<.001]$ and the interaction Feature by Presence $[\mathrm{F}$ $(2,12)=25.835, p<.001]$ were highly significant because 5 -y-o children were much more accurate in recognizing noFeature (error rate $=19.3 \%$ ) than onlyFeature stimuli (error rate $=42.7 \%$ ). Needless to say, the stimuli onlyEyes (error rate $=11.5 \%)$ were recognized much better than both onlyMouth $(50.5 \%)$ and onlyNose $(66.1 \%)$ stimuli, while the opposite was true for noFeature stimuli with noEyes $(42.7 \%)$ recognized much worse than noMouth $(9.9 \%)$ and noNose sti- 
muli (5.2\%).

Findings from experiment 3 were straightforward. The relatively bad performance of adult participants when requested to recognize upside down stimuli further demonstrates that inversion is especially detrimental to the processing of faces (Valentine, 1988), likely because disrupts local configural processing (Bartlett \& Searcy, 1993; Boutsen \& Humphreys, 2003). In turn, the performance of the three age groups with natural, canonical, upright stimuli, confirms that the facial feature "eyes" is recognized much better than the facial feature "mouth", which, in turn, is recognized better than the facial feature "nose". These results are strongly consistent with previous findings (Hay \& Cox, 2000; Taylor et al., 2001; Pellicano et al., 2006; Ge et al., 2008) as well as with findings from experiment 2 claiming that the eyes are the most influential facial feature in the judgment of familiar, own-age, faces.

\section{Conclusion}

Three experiments were carried out to investigate how adults and children perceive whole faces, face and body parts.

Results were straightforward in demonstrating that adults are very expert at recognizing whole faces as well as and body and face parts of themselves and their friends. In particular, it was strongly emphasized the relevance of the eyes as the most influential facial feature (Hay \& Cox, 2000; Taylor et al., 2001; Pellicano et al., 2006; Itier et al., 2007). Furthermore, at least when presented with very familiar stimuli and requested to perform quite ecological, relatively challenging, tasks, adult perceivers did not show any evidence of self effect (Keyes \& Brady, 2010) nor of gender difference, thus failing to support the hypothesis of a female superiority in face processing (Cellerino, Borghetti, \& Sartucci, 2004; McBain, Norton, \& Chen, 2009; Sun, Gao, \& Han, 2010). Finally, adults' performance with upside down stimuli confirms the deleterious effects of inversion upon face (and face parts) recognition (Valentine, 1988; Bartlett \& Searcy, 1993; Boutsen \& Humphreys, 2003).

This research, however, was mainly aimed at elucidating the abilities of children of different ages to recognize faces and facial features of themselves and their friends. A quite large sample of typically developing children from two age groups was enrolled in the study: 32 participants aged 5 years, and 16 participants aged 8 years. In both groups, females and males were equally distributed. Beyond the intrinsic limitations of a cross-sectional and not a longitudinal study, the results provided further insight into the developmental course of face and facial features processing. First, it was clear that, despite its early appearance, the expertise in face processing develops slowly over many years (Macchi Cassia, 2011) so that relevant behavioral differences emerge even when two narrow age cohorts are examined. In particular, while at 5 years of age children are already very able to recognize familiar, whole faces, they are still coarse and imprecise when requested to recognize body and face parts in isolation or-even in a lesser 
degree-inserted into a face contour. This ability, however, improves during middle childhood, although 8-y-o perceivers still show a pattern of performance different from that observed among adults. Findings from this study are also clearly consistent with the hypothesis that the abilities to process the different internal facial features follow different, specific, developmental courses and processing of the eyes begins and matures earlier (Taylor et al., 2001), so that the eyes are much more influential than the mouth and the nose in identity judgments of familiar faces (Hay \& Cox, 2000; Pellicano et al., 2006).

Given that self recognition seems to be present from 4 years of age (Frassinetti et al., 2012), one could have expected to observe a strong self-face effect among 5-y-o and 8-y-o participants with self-faces recognized easier and faster than other identities (Brédart, Delchambre, \& Laureys, 2006; Keyes \& Brady, 2010). Quite surprisingly, both 5-y-o and 8-y-o children turned out to be faster in recognizing SG and OG than Self faces. Far from disconfirming the presence of self recognition in the age cohorts under examination, this apparently paradoxical finding can be taken as supportive evidence of the idea that self-faces grab and maintain more attention than other identities, so that perceivers tend to look at their own face longer, rather than to find it faster (Devue et al., 2009).

A final consideration concerns gender differences in facial processing. Although, further investigation with a larger sample of participants is required to substantiate claims regarding a developmental advantage for female children in face processing, the trends seen in the data presented here seem quite robust. Previous observations are consistent with the hypothesis that the development of face processing abilities mainly depends on experience with faces rather than to age-related changes in face processing (Ge et al., 2008). Thus, it seems reasonable that face processing abilities mature earlier in females than males because females are more involved in human relationships and so more experienced with faces.

\section{Acknowledgements}

I wish to thank F. Taccola, R. Spina, and S. Lottini for their help with data collection. The financial contribution of MIUR is also gratefully acknowledged.

\section{Conflicts of Interest}

The author declares no conflicts of interest regarding the publication of this paper.

\section{References}

Bank, S., Rhodes, G., Read, A., \& Jeffery, L. (2015). Face and Body Recognition Show Similar Improvement during Childhood. Journal of Experimental Child Psychology A 137, 1-11. https://doi.org/10.1016/j.jecp.2015.02.011

Bartlett, J. C., \& Searcy, J. (1993). Inversion and Configuration of Faces. Cognitive Psychology, 25, 281-316. https://doi.org/10.1006/cogp.1993.1007

Bonner, L., \& Burton, M. (2004). 7-11-Year-Old Children Show an Advantage for Matching 
and Recognizing the Internal Features of Familiar Faces: Evidence against a Developmental Shift. Quarterly Journal of Experimental Psychology A, 57, 1019-1029. https://doi.org/10.1080/02724980343000657

Boutsen, L., \& Humphreys, G. W. (2003). The Effect of Inversion on the Encoding of Normal and "Thatcherized" Faces. Quarterly Journal of Experimental Psychology A, 56, 955-975. https://doi.org/10.1080/02724980244000774

Brédart, S., Delchambre, M., \& Laureys, S. (2006). Short Article One's Own Face Is Hard to Ignore. Quarterly Journal of Experimental Psychology, 59, 46-52. https://doi.org/10.1080/17470210500343678

Campbell, R., Coleman, M., Walker, J., Benson, P. J., Wallace, S., Michelotti, J. et al. (1999). When Does the Inner-Face Advantage in Familiar Face Recognition Arise and Why? Visual Cognition, 6, 197-216. https://doi.org/10.1080/713756807

Campbell, R., Walker, J., \& Baron-Cohen, S. (1995). The Development of Differential Use of Inner and Outer Face Features in Familiar Face Identification. Journal of Experimental Child Psychology, 59, 196-210. https://doi.org/10.1006/jecp.1995.1009

Carey, S., \& Diamond, R. (1977). From Piecemeal to Configurational Representation of Faces. Science, 195, 312-314. https://doi.org/10.1126/science.831281

Carey, S., Diamond, R., \& Woods, B. (1980). Development of Face Recognition: A Maturational Component? Developmental Psychology, 16, 257-269. https://doi.org/10.1037/0012-1649.16.4.257

Cellerino, A., Borghetti, D., \& Sartucci, F. (2004). Sex Differences in Face Gender Recognition in Humans. Brain Research Bulletin, 63, 443-449. https://doi.org/10.1016/j.brainresbull.2004.03.010

Clutterbuck, R., \& Johnston, R. A. (2004). Demonstrating the Acquired Familiarity of Faces by Using a Gender-Decision Task. Perception, 33, 159-168. https://doi.org/10.1068/p5115

Crookes, K., \& McKone, E. (2009). Early Maturity of Face Recognition: No Childhood Development of Holistic Processing, Novel Face Encoding, or Face-Space. Cognition, 111, 219-247. https://doi.org/10.1016/j.cognition.2009.02.004

De Heering, A., Houthuys, S., \& Rossion, B. (2007). Holistic Face Processing Is Mature at 4 Years of Age: Evidence from the Composite Face Effect. Journal of Experimental Child Psychology, 96, 57-70. https://doi.org/10.1016/j.jecp.2006.07.001

Devue, C., Van der Stigchel, S., Brédart, S., \& Theeuwes, J. (2009). You Do Not Find Your Own Face Faster; You Just Look at It Longer. Cognition, 111, 114-122. https://doi.org/10.1016/j.cognition.2009.01.003

Ellis, H. D., Shepherd, J. W., \& Davies, G. M. (1979). Identification of Familiar and Unfamiliar Faces from Internal and External Features: Some Implications for Theories of Face Recognition. Perception, 8, 431-439. https://doi.org/10.1068/p080431

Frassinetti, F., Fiori, S., D’Angelo, V., Magnani, B., Guzzetta, A., Brizzolara, D., \& Cioni, G. (2012). Body Knowledge in Brain-Damaged Children: A Double-Dissociation in Self and Other's Body Processing. Neuropsychologia, 50, 181-188. https://doi.org/10.1016/j.neuropsychologia.2011.11.016

Ge, L., Anzures, G., Wang, Z., Kelly, D. J., Pascalis, O., Quinn, C. et al. (2008). An Inner Face Advantage in Children's Recognition of Familiar Peers. Journal of Experimental Child Psychology, 101, 124-136. https://doi.org/10.1016/j.jecp.2008.05.006

Goren, C. C., Sarty, M., \& Wu, P. Y. (1975). Visual Following and Pattern Discrimination of Face-Like Stimuli by Newborn Infants. Pediatrics, 56, 544-549.

Hay, D. C., \& Cox, R. (2000). Developmental Changes in the Recognition of Faces and 
Facial Features. Infant and Child Development, 9, 199-212.

https://doi.org/10.1002/1522-7219(200012)9:4<199::AID-ICD231>3.0.CO;2-K

Hillairet de Boisferon, A., Uttley, L., Quinn, P. C., Lee, K., \& Pascalis, O. (2014). Female Face Preference in 4-Month-Olds: The Importance of Hairline. Infant Behavior and Development, 37, 676-681. https://doi.org/10.1016/j.infbeh.2014.08.009

Itier, R. J., Alain, C., Sedore, K., \& McIntosh, A. R. (2007). Early Face Processing Specificity: It's in the Eyes! Journal of Cognitive Neuroscience, 119, 1815-1826. https://doi.org/10.1162/jocn.2007.19.11.1815

Kanwisher, N., McDermott, J., \& Chun, M. M. (1997). The Fusiform Face Area: A Module in Human Extrastriate Cortex Specialized for Face Perception. Journal of Neuroscience, 17, 4302-4311. https://doi.org/10.1523/JNEUROSCI.17-11-04302.1997

Kelly, D. J., Quinn, P. C., Slater, A. M., Lee, K., Ge, L., \& Pascalis, O. (2007). The Other-Race Effect Develops during Infancy. Psychological Science, 18, 1084-1089. https://doi.org/10.1111/j.1467-9280.2007.02029.x

Keyes, H., \& Brady, N. (2010). Self-Face Recognition Is Characterized by "Bilateral Gain” and by Faster, More Accurate Performance Which Persists When Faces Are Inverted. Quarterly Journal of Experimental Psychology, 63, 840-847. https://doi.org/10.1080/17470211003611264

Kuefner, D., de Heering, A., Jacques, C., Palmero-Soler, E., \& Rossion B. (2009). Early Visually Evoked Electrophysiological Responses over the Human Brain Show Stable Patterns of Face-Sensitivity from 4 Years to Adulthood. Frontiers in Human Neuroscience, 3, 67. https://doi.org/10.3389/neuro.09.067.2009

Kuefner, D., Macchi Cassia, V., Picozzi, M., \& Bricolo, E. (2008). Do All Kids Look Alike? Evidence for an Other-Age Effect in Adults. Journal of Experimental Psychology: Human Perception and Performance, 34, 811-817. https://doi.org/10.1037/0096-1523.34.4.811

Lewin, C., \& Herlitz, A. (2002). Sex Differences in Face Recognition-Women's Faces Make the Difference. Brain and Cognition, 50, 121-128. https://doi.org/10.1016/S0278-2626(02)00016-7

Longmore, C. A., Liu, C. H., \& Young, A. W. (2015). The Importance of Internal Facial Features in Learning New Faces. Quarterly Journal of Experimental Psychology, 68, 249-260. https://doi.org/10.1080/17470218.2014.939666

Macchi Cassia, V. (2011). Age Biases in Face Processing: The Effects of Experience Across Development. British Journal of Psychology, 102, 816-829. https://doi.org/10.1111/j.2044-8295.2011.02046.x

Martini, M., Bufalari, I., Stazi, M. A., \& Aglioti, S. M. (2015). Is That Me or My Twin? Lack of Self-Face Recognition Advantage in Identical Twins. PLOS ONE, 10, e0120900. https://doi.org/10.1371/journal.pone.0120900

McBain, R., Norton, D., \& Chen, Y. (2009). Females Excel at Basic Face Perception. Acta Psychologica, 130, 168-173. https://doi.org/10.1016/j.actpsy.2008.12.005

Minnebusch, D. A., \& Daum, I. (2009). Neuropsychological Mechanisms of Visual Face and Body Perception. Neuroscience \& Biobehavioral Reviews, 33, 1133-1144. https://doi.org/10.1016/j.neubiorev.2009.05.008

Mondloch, C. J., Dobson, K. S., Parsons, J., \& Maurer, D. (2004). Why 8-Year-Olds Cannot Tell the Difference between Steve Martin and Paul Newman: Factors Contributing to the Slow Development of Sensitivity to the Spacing of Facial Features. Journal of Experimental Child Psychology, 89, 159-181. https://doi.org/10.1016/S0022-0965(04)00108-0

Mondloch, C. J., Geldart, S., Maurer, D., \& Le Grand, R. (2003). Developmental Changes 
in Face Processing Skills. Journal of Experimental Child Psychology, 86, 67-84. https://doi.org/10.1016/S0022-0965(03)00102-4

Morton, J., \& Johnson, M. H. (1991). CONSPEC and CONLERN: A Two-Process Theory of Infant Face Recognition. Psychological Review, 98, 164-181. https://doi.org/10.1037/0033-295X.98.2.164

Pellicano, E., Rhodes, G., \& Peters, M. (2006). Are Preschoolers Sensitive to Configural Information in Faces? Developmental Science, 9, 270-277. https://doi.org/10.1111/j.1467-7687.2006.00489.x

Proietti, V., Pisacane, A., \& Macchi Cassia, V. (2013). Natural Experience Modulates the Processing of Older Adult Faces in Young Adults and 3-Year-Old Children. PLoS ONE, 8, e57499. https://doi.org/10.1371/journal.pone.0057499

Schwarzer, G. (2000). Development of Face Processing: The Effect of Face Inversion. Child Development, 71, 391-401. https://doi.org/10.1111/1467-8624.00152

Schwarzer, G., \& Massaro, D. W. (2001). Modeling Face Identification Processing in Children and Adults. Journal of Experimental Child Psychology, 79, 139-161. https://doi.org/10.1006/jecp.2000.2574

Sugimura, T. (2013). Young Children's Difficulty in Disregarding Information from External Features When Matching Unfamiliar Faces. Journal of Experimental Child Psychology, 116, 296-308. https://doi.org/10.1016/j.jecp.2013.06.011

Sun, Y., Gao, X., \& Han, S. (2010). Sex Differences in Face Gender Recognition: An EventRelated Potential Study. Brain Research, 1327, 69-76. https://doi.org/10.1016/j.brainres.2010.02.013

Taylor, M. J., Batty, M., \& Itier, R. J. (2004). The Faces of Development: A Review of Early Face Processing over Childhood. Journal of Cognitive Neuroscience, 16, 1426-1442. https://doi.org/10.1162/0898929042304732

Taylor, M. J., Edmonds, G. E., McCarthy, G., \& Allison, T. (2001). Eyes First! Eye Processing Develops before Face Processing in Children. Cognitive Neuroscience and Neuropsychology, 12, 1671-1676. https://doi.org/10.1097/00001756-200106130-00031

Valentine, T. (1988). Upside-Down Faces: A Review of the Effect of Inversion upon Face Recognition. British Journal of Psychology, 79, 471-491. https://doi.org/10.1111/j.2044-8295.1988.tb02747.x

Valenza, E., Simion, F., Cassia, V. M., \& Umiltà, C. (1996). Face Preference at Birth. ournal of Experimental Psychology: Human Perception and Performance, 22, 892-903. https://doi.org/10.1037/0096-1523.22.4.892

Want, S. C., Pascalis, O., Coleman, M., \& Blades, M. (2003). Face Facts: Is the Development of Face Recognition in Early and Middle Childhood Really So Special? In O. Pascalis, \& A. Slater (Eds.), The Development of Face Processing in Infancy and Early Childhood. Current Perspectives (pp. 209-219). New York: Nova Science Publishers, Inc.

Willis, J., \& Todorov, A. (2006). First Impressions: Making up Your Mind after a 100-Ms Exposure to a Face. Psychological Science, 17, 592-598. https://doi.org/10.1111/j.1467-9280.2006.01750.x

Wilson, R., Blades, M., \& Pascalis, O. (2007). Familiar Face Recognition in Children with Autism: The Differential Use of Inner and Outer Face Parts. Journal of Autism Developmental Disorders, 37, 314-320. https://doi.org/10.1007/s10803-006-0169-Z

Wu, H., Yang, S., Sun, S., Liu, C., \& Luo, Y. J. (2013). The Male Advantage in Child Facial Resemblance Detection: Behavioral and ERP Evidence. Social Neuroscience, 8, 555-567. https://doi.org/10.1080/17470919.2013.835279 
Young, A. W., Hay, D. C., McWeeny, K. H., Flude, B. M., \& Ellis, A. W. (1985). Matching Familiar and Unfamiliar Faces on Internal and External Features. Perception, 14, 737746. https://doi.org/10.1068/p140737 